\title{
The job search journey of Portuguese Millennials: a qualitative exploratory study
}

Job search journey of Portuguese Millennials

Sandra Miranda and Carolina Duarte

Department of Management, Advance/CSG, ISEG - Lisbon School of Economics \& Management, Universidade de Lisboa, Lisboa, Portugal

\begin{abstract}
Purpose - This study aims to research the job search journey of Portuguese Millennials. A job search journey is defined as the contact points between organisations and candidates throughout the job search process and the flow of this journey.

Design/methodology/approach - Data were collected through in-depth, semi-structured interviews with 13 individuals.

Findings - This paper shows that the contact points established by individuals during the first stage of their job search influence the subsequent contact points chosen to gather information about the organisation and also the journey undertaken up until the decision is made to apply for the job.

Originality/value - This research intends to contribute to the existing literature in two ways: it proposes a new concept which is designated the job search journey, and it maps out the job search journey of Portuguese Millennials.
\end{abstract}

Keywords Job search, Job-seeker, Millennials, Qualitative study

Paper type Research paper

\section{Introduction}

As a large number of communication channels are now readily available, both the attraction of new candidates by companies and the search for employment by candidates can be carried out in different ways. The internet has increased the number of possible activities that an individual can utilise for their job search (Bae \& Mowbray, 2019), and consequently, it has expanded the number of recruitment activities available for organisations. Both this heterogeneity of communication channels and the relatively easy access to information help simplify the decision-making process for candidates; however, they give rise to increased difficulties for organisations (Wolny \& Charoensuksai, 2014). For this reason, it is increasingly important for companies to understand this search process well to enable them

(C) Sandra Miranda and Carolina Duarte. Published in European Journal of Management Studies. Published by Emerald Publishing Limited. This article is published under the Creative Commons Attribution (CC BY 4.0) licence. Anyone may reproduce, distribute, translate and create derivative works of this article (for both commercial and non-commercial purposes), subject to full attribution to the original publication and authors. The full terms of this licence maybe seen at http:// creativecommons.org/licences/by/4.0/legalcode

The authors gratefully acknowledge financial support from FCT- Fundação para a Ciencia e Tecnologia (Portugal), national funding through research grant UIDB/04521/2020.

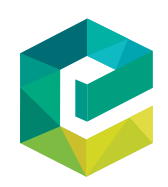

European Journal of Management Studies 
EJMS

25,2

to position themselves and be able to capture candidates' attention effectively (Backhaus \& Tikoo, 2004; Howardson \& Behrend, 2014).

To create job awareness and attract (the right) candidates, there must be congruence between job search and organisations' recruitment activities (Acikgoz, 2018; Uggerslev, Fassina, \& Kraichy, 2012). When there is a lack of fit between the recruitment channels used by individuals to search for a job and those used by organisations to search for candidates, the outcome of the activities of both individuals and organisations tends to be ineffective in creating "job awareness" for the right candidates.

Based on past research, Acikgoz (2018) posits that job seekers' characteristics can influence the type of job search activities that they carry out. This assertion is supported by various empirical studies. For example, the results of a meta-analysis by Kanfer, Wanberg, and Kantrowitz (2001) show that individual-level variables, such as personality, selfefficacy, needs, and social support are significantly related to job search behaviour. Another study by Newman and Lyon (2009) shows that demographic variables, such as age, gender or location can influence the sources which job seekers use when searching for a job. One individual factor which is also likely to influence the type of job search activities carried out by job seekers is the generational group to which the individual belongs. In fact, past studies have shown that generations differ in several work-related aspects, such as their personalities, work values, work attitudes, teamwork and leadership preferences, career patterns, and work-life balance (Lyons \& Kuron, 2014).

The idea that generations are different is controversial. Two main arguments are presented by human resource management researchers. The first is that, generalisations about generations are difficult, due to the fact that the evidence available is fractured and contradictory (Lyons \& Kuron, 2014). Secondly, it is hard to separate generational effects from age-related dynamics (Lyons \& Kuron, 2014; Rudolph, Rauvola, \& Zacher, 2018). However, despite these challenges, Lyons and Kuron (2014), in their critical review of past empirical studies, contend that generational differences are robust.

Thus, the purpose of this study is to specifically understand the route that the candidates of the Portuguese Millennial generation follow, and the communication channels that they use - from the moment that they recognise that they have to search for a job, up until they receive a response regarding whether they have been selected, or not. By doing so, this study proposes a new concept which is designated the "job search journey". The concept of the job search journey aims to describe the various contact points that exist between candidates and companies throughout the job search process. The proposed concept is inspired by the field of marketing and consumer behaviour, where the term "customer journey" or "buyer journey" is used to describe the various points of contact between companies and customers throughout the purchasing decision process (Rosenbaum, Otalora, \& Ramírez, 2017). Just as clients partake in a series of interactions with brands and engage in a process of gathering information which helps them make a purchasing decision, job candidates are also subject to a series of interactions involving several contact points with the organisations where they collect information that is required to enable them to submit their application and eventually accept a job offer.

The primary use of a job search journey is to help organisations achieve a fit between job search and the organisation's recruitment activities, which, as mentioned above, is very important for a successful recruitment strategy. Additionally, a job search journey can result in recruitment companies improving applicants' experience at the various contact points throughout their job search process.

The choice of the Millennials generation is due to the fact that this generation is considered to be a very attractive potential market for organisations (Kotler \& Armstrong, 2018). Indeed, in 
the USA alone, Millennials comprise approximately 83 million people, and, by 2025, this generation is estimated to represent three-quarters of the global workforce (EY, 2015).

To map the job search journey of the Portuguese Millennial generation, this study uses the job search stages identified by Acikgoz (2018):

- job search activities and job awareness;

- information collection;

- evaluation and shortlist of possible jobs;

- application' intention and applications;

- persuasion; and

- outcomes.

With this research, we hope to contribute to the human resources management literature in two ways:

(1) We address the call for more research on individual characteristics which can influence candidates' job search strategies.

(2) We propose a new concept - the 'job search journey' - to refine our knowledge of the job search strategies of job seekers.

\section{Job search process and the points of contact between candidates and the organisation}

The job search process determines the set of alternatives and the job opportunities for which an individual may choose to apply for, as well as the quantity and type of information that can be used in decision making (Barber, Daly, Giannantonio, \& Phillips, 1994). Candidates select their methods and communication channels by taking into consideration their suitability to their needs (Wolny \& Charoensuksai, 2014) and accordingly select the best job search strategies and communication channels used by organisations to disseminate their job offers (Weber \& Mahringer, 2008).

Based on an extensive review of the literature, Acikgoz (2018) proposes an integrated model for job search and the recruitment of new employees, which serves as the basis for the following sections of our literature review.

\subsection{Job search activities and job awareness}

During the search phase, candidates realise that they need to start their job search and subsequently carry out a set of actions with the objective of identifying opportunities in the job market (Acikgoz, 2018). Awareness occurs when individuals and organisations become conscious of each other's existence and corresponds to the time at which candidates become aware of a particular company or job vacancy. According to Acikgoz (2018), in order for this knowledge to take place, there must be convergence between the channels preferred by candidates for their job search and the channels used by the companies to communicate a particular job vacancy or its employer brand.

Social media networks provide organisations with increased visibility of their offer of job vacancies and enable them to reach more qualified candidates (Prajapati, 2016). In Jansson's (2016) study of the Millennials generation regarding job search, LinkedIn emerged as the preferred social media platform, due to the current relevance of this social network and the number of job opportunities it provides. Candidates also visit websites fairly frequency of companies about which they have some knowledge and an interest in working for. Those 
EJMS

25,2

who are more likely to directly consult organisations' websites tend to have a more or less clear idea of where they want to work (Acikgoz \& Bergman, 2016). According to Acikgoz and Bergman (2016), organisations need to focus more on the use of job placement websites at an early stage during the recruitment and selection process, as this medium plays an important role in the search for offers by candidates.

State-run employment centres continue to be a popular method for looking for work amongst Millennials (Bae \& Mowbray, 2019). In the study by Addison and Portugal (2002), consulting public employment centres was the most frequent method used, followed by resorting to personal contacts and direct contact with the employer. Furthermore, Corcoran, Datcher, and Duncan (1980) concluded that a large number of candidates become aware of their current job through personal contacts.

Educational institutions often create career departments, with the aim of inserting young people into the job market, assuming the responsibility for the professional allocation of their students. The role of these career departments is to provide students or recent graduates with both information regarding job vacancies and resources and advice for their students in their quest to become better professionals, and also to encourage the development of activities that will bring these potential candidates closer to the job market by organising job fairs, for example. Companies target new talent which is about to enter the job market at job fairs by publicising job opportunities, which has a positive impact on both organisations and candidates (Beam, 2016).

\subsection{Information collection}

The information collection phase occurs after the candidate has recognised the opportunities available in the job market - based on matching the needs and desires of both the candidate and the organisation. That is to say, as candidates proceed to search for detailed information about previously encountered opportunities, their perception of the similarity or dissimilarity with their desired goal influences whether they become attracted to the potential job and the organisation and if they subsequently intend to apply for the position (Acikgoz, 2018).

It is at this stage that it is expected that candidates use other types of channels to obtain more detailed information about each of the identified job opportunities (Acikgoz \& Bergman, 2016). According to these authors, similar to their search activities, candidates may resort to using tools such as social media networks and institutional websites to search for more information. However, the form and the intention with which these digital media are used differ. In the study by Acikgoz and Bergman (2016) regarding the use of different social media networks in recruitment and selection, it was found that although only a small proportion of the respondents used Facebook during the search phase of looking for job opportunities, the use of this social media network increased during the information collection phase. In the case of LinkedIn, the majority of respondents claimed to use this network to encounter job opportunities, although only a small percentage of them used it to gather further detailed information. Social media networks can still be a potential source of information for candidates when they come in contact with employees who are currently working for an organisation that they would like to work for (Acikgoz \& Bergman, 2016). In addition, company websites also provide up-to-date and complete information and are a very useful channel for this information-collecting phase (Acikgoz \& Bergman, 2016).

The use of online review websites (e.g. Glassdoor.com) is a recent practice, which allows candidates and current and former employees to exchange views about the selection process, compensation package, and the benefits offered by companies. 
University-organised job fairs provide candidates with the opportunity to have close contact with various organisations simultaneously and to be able to obtain information regarding the various aspects of these organisations' professional activity (Beam, 2016). Furthermore, job fairs allow candidates to gain a comprehensive view of the prevailing trends in the job market (Beam, 2016).

2.3 Evaluation and shortlist of possible jobs, application' intention, applications, persuasion, and outcomes

After having collected information regarding the aspects that characterise the organisation and the position for which they are applying, candidates then evaluate the strong and weak points of each of the options, based on the information that they have previously collected (Acikgoz, 2018). Candidates only evaluate and weigh their options at this stage, deciding later on whether to include them in a shortlist of possible jobs. This shortlist consists of a list of vacancies or organisations for which the candidate intends to apply. It is this list that is the basis for deciding whether to formalise an interest in working for the organisation, or not.

In Jansson's (2016) study of the Millennials generation, in the cases when only one intention is decided on during the pre-application phase, it was concluded that it was at this point that some candidates would like to receive a contact from the organisation, to have an opportunity to gather more information about the position to which they might apply. Furthermore, in the same study, it was verified that, after submitting a job application, candidates expect to receive a confirmation of receipt of their application from the company, with electronic mail being the preferred channel for this type of contact.

The selection stages of potential candidates follow the submission of a job application by interested candidates (Acikgoz, 2018). This stage is usually comprised of interviews, tests, and examinations, all of which are crucial for attracting talent, as they provide candidates with the opportunity to gather first-hand information regarding the potential future workplace (Acikgoz, 2018). In the study by Jansson (2016), respondents indicated that it would be useful to be contacted by a company employee during the recruitment and selection process, to clarify any doubts.

Nowadays, it is common for psychometric tests and online assessments to be an integral part of the recruitment and selection processes of companies. The adoption of this strategy by companies is seen by the candidates to be preferable to a face-to-face test or interview (Jansson, 2016). With regards video interviews, when asked about their preference for a faceto-face interview or one via Skype, candidates preferred the former (Jansson, 2016).

The outcome phase refers to the determination and communication of the final result after having carried out the selection process. Candidates expect to receive feedback regarding their performance from the organisation after the final selection tests have been carried out, be it positive or negative (Jansson, 2016). It is important for organisations to establish this contact, for if they do not do so, they may not only lose a qualified candidate to the competition, but they might also run the risk of damaging the image of the company (Smith \& Rupp, 2004).

Although the phases of applications' intention, application, persuasion and outcomes are beyond the control of candidates in terms of their choice of interaction and communication channels with the company, it was decided to include these factors in our review of the literature and also in the interview script, bearing in mind the exploratory nature of this study. Figure 1 presents a summary of the communication channels most used by Millennials at each stage of the job search process. The various stages of the job search process are listed in the upper part of the figure, in accordance with the Acikgoz (2018)

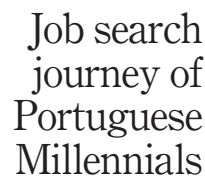




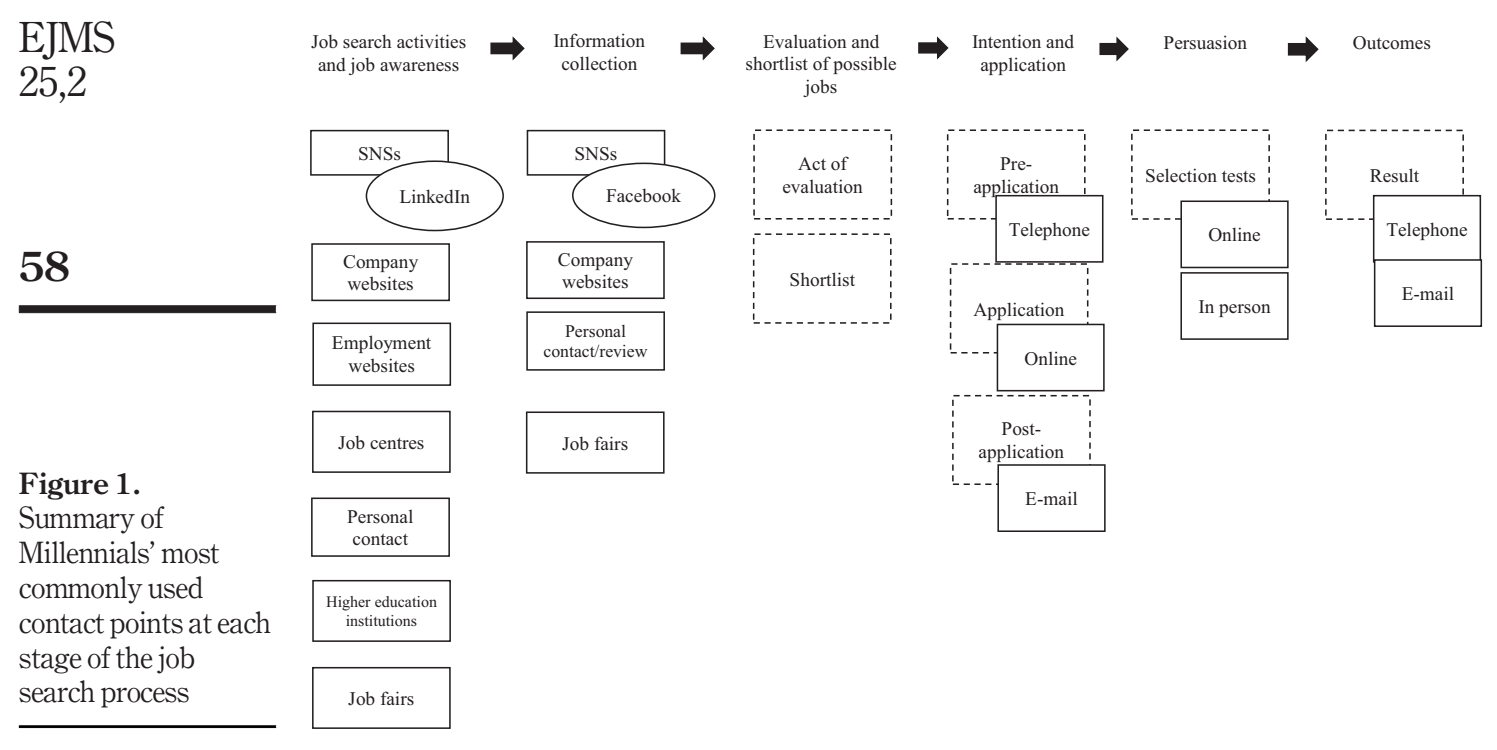

model. The dashed boxes represent sub-phases of the job search process, as identified in the research of Acikgoz (2018) and Jansson (2016). Continuous-line boxes represent possible points of contact between candidates and organisations, whilst oval figures represent examples of communication channels.

\section{Methodology}

This study used a qualitative research design, based on the use of interviews as a datacollection technique. The study is exploratory and is aimed at understanding the meanings attributed by the interviewees and their relationships (Saunders, Lewis, \& Thornhill, 2016). Accordingly, it is not possible to make any generalisation regarding the Portuguese Millennials generation.

There is no consensus in the literature regarding the age group of the population to which the Millennials generation belongs (Ng \& Johnson, 2015; Doster, 2013). Typically, the Millennials, who are also known as "Generation Y" or "GenY", are the generational cohort born between the early 1980s and the mid-1990s to 2000 (Rudolph, Rauvola, \& Zacher, 2018). In this research, the study's population were all individuals of the Millennial generation, of age 19-36 (Twenge, Campbell, Hoffman, \& Lance, 2010), who were currently residing in Portugal, and who were either looking for a job at the time, or had carried out a job search process during the last two years (Table 1). Following Weiss's (1994) strategy of maximising the coverage of respondents, we sought to obtain a sample that was as diversified as possible in terms of gender, level of education, and employment status. The convenience sample is composed of 13 individuals, 9 females and 4 males, aged between 21 and 26 years. The distribution of the highest level of completed schooling of the respondents ranges from secondary education (three respondents), bachelors (seven respondents) and masters (three respondents). Their employment situation varies from student-worker attending a trainee programme (four respondents), part-time student-worker (one respondent), full-time student-worker (one respondent), employed (six respondents) and job-seeking student (one respondent). All 


\begin{tabular}{|c|c|c|}
\hline Name & Sociodemographic data & journey of \\
\hline \multirow[t]{4}{*}{ Interviewee 1} & Age: 23 years old & Portuguese \\
\hline & Nationality: Portuguese & Millennials \\
\hline & $\begin{array}{l}\text { Area of residence: Lisbon } \\
\text { Emplovment status: student worker attending a trainee programme }\end{array}$ & \\
\hline & $\begin{array}{l}\text { Employment status: student worker attending a trainee programme } \\
\text { Education: Bachelors in Management, and enrolled in the Masters in Marketing }\end{array}$ & \\
\hline \multirow[t]{5}{*}{ Interviewee 2} & Age: 24 years old & 59 \\
\hline & Nationality: Portuguese & \\
\hline & Area of residence: Lisbon & \\
\hline & Employment status: student worker attending a trainee programme & \\
\hline & Education: Bachelors in Management, and enrolled in the Masters in Economics & \\
\hline \multirow{5}{*}{ Interviewee 3} & Age: 23 years old & \\
\hline & Nationality: Portuguese & \\
\hline & Area of residence: Lisbon & \\
\hline & Employment Status: employed & \\
\hline & Education: Bachelors in Management, and enrolled in the Masters in Marketing & \\
\hline \multirow[t]{6}{*}{ Interviewee 4} & Age: 23 years old & \\
\hline & Nationality: Portuguese & \\
\hline & Area of residence: Lisbon & \\
\hline & Employment Status: employed & \\
\hline & Education: Masters in Management, with specialisation in International Business & \\
\hline & Strategy & \\
\hline \multirow{5}{*}{ Interviewee 5} & Age: 24 years old & \\
\hline & Nationality: Portuguese & \\
\hline & Area of residence: Lisbon & \\
\hline & Employment Status: employed & \\
\hline & Education: Masters in Finance & \\
\hline \multirow[t]{6}{*}{ Interviewee 6} & Age: 23 years old & \\
\hline & Nationality: Portuguese & \\
\hline & Area of residence: Lisbon & \\
\hline & Employment status: student worker attending a trainee programme & \\
\hline & Education: Bachelors in Human Resources Management, and enrolled in the Masters & \\
\hline & $\begin{array}{l}\text { In Human Resources Management } \\
\text { Age. } 26 \text { vears old }\end{array}$ & \\
\hline \multirow{4}{*}{ Interviewee 7} & Nationality: Portuguese & \\
\hline & Area of residence: Lisbon & \\
\hline & Employment status: part-time student-worker & \\
\hline & Education: Enrolled in the Bachelors in Management & \\
\hline \multirow[t]{5}{*}{ Interviewee 8} & Age: 23 years old & \\
\hline & Nationality: Portuguese & \\
\hline & Area of residence: Funchal & \\
\hline & Employment status: employed & \\
\hline & Education: High School diploma & \\
\hline \multirow[t]{5}{*}{ Interviewee 9} & Age: 21 years old & \\
\hline & Nationality: Portuguese & \\
\hline & Area of residence: Lisbon & \\
\hline & Employment Status: employed & \\
\hline & Education: High School diploma & \\
\hline \multirow[t]{6}{*}{ Interviewee 10} & Age: 23 years old & \\
\hline & Nationality: Portuguese & \\
\hline & Area of residence: Lisbon & \\
\hline & Employment status: student worker attending a trainee programme Education: & \\
\hline & Bachelors in Management, and enrolled in the Masters in Marketing & Table 1. \\
\hline & (continued) & Sample description \\
\hline
\end{tabular}




\section{EJMS \\ 25,2}

60

Interviewee 12

Interviewee 13

Table 1.

\begin{tabular}{ll}
\hline Name & Sociodemographic data \\
\hline Interviewee 11 & Age: 24 years old \\
& Nationality: Portuguese \\
& Area of residence: Lisbon \\
& Employment status: full-time student-worker \\
& Education: Bachelors in Communication, and enrolled in the Masters in Marketing \\
Anterviewee 12 & Age years old \\
& Nationality: Portuguese \\
& Area of residence: Lisbon \\
& Employment Status: employed \\
& Education: Masters in Human Resource Development Policies \\
& Age: 24 years old \\
& Nationality: Portuguese \\
& Area of residence: Lisbon \\
& Employment Status: job-seeking student \\
& Education: Bachelors in Management, and enrolled in the Masters in Marketing \\
\end{tabular}

respondents resided in the Lisbon area of Portugal at the time of the study, except for one, who lived in Funchal, Madeira.

The interview questions (available upon request to the authors) were chosen based on the literature review. The second author carried out all the interviews, which thus avoided variance between interviewers due to differences in experience and the method of conducting the interview. All respondents signed an informed consent form, which explained the scope and objectives of the study and assured them the confidentiality and anonymity of the information collected, and clarified that no benefits were to be granted for participating in the study. The interviews lasted between 30 and $90 \mathrm{~min}$ and were recorded and transcribed.

Respondents were asked to present and requested their socio-demographic information. All the interviewees were asked the same open questions, in accordance with the interview script (Appendix 1). The questions were divided into six blocks, in line with the Acikgoz (2018) model, namely:

(1) job search activities and job awareness;

(2) information collection;

(3) evaluation and shortlist of possible jobs;

(4) application' intention and applications;

(5) persuasion; and

(6) outcomes.

Each phase was described in full to the interviewees. For each phase, the respondents were asked about:

- the sources and information channels used;

- the reasons for their use; and

- the interactions that they have had with organisations throughout their job searches. 
Following a directed approach to qualitative content analysis (Lune \& Berg, 2017), all comments (where applicable) were categorised according to the theoretical framework of Acikgoz (2018). The coding of the comments followed the tripartite process suggested by Richards (2015) of descriptive, by topic, and analytical coding. All comments were selected and grouped into "themes" which reflect the meaning attributed by the respondents (Appendix 2).

\section{Presentation of the results}

Job search activities and job awareness: during the interviews, all respondents said that they used social media networks as a search tool for job opportunities. The main reason why social media networks are used so much at this stage is because this medium can condense numerous job vacancies of several organisations into one place, while simultaneously providing easy contact with each of the organisations.

The social media network of choice for identifying job opportunities was LinkedIn, which was used by 11 of the 13 respondents. One respondent said that his search was essentially conducted through LinkedIn - which provides a broader view of all the opportunities available in the market, more quickly. [...] "as it is a tool which ends up showing the same offers that are on a company's own website" (Interviewee 2, 24 years old, Bachelors graduate). Contrary to this idea that LinkedIn is the best tool to look for a job, Interviewee 1 (a 23 years old Bachelors graduate) stated that, despite using LinkedIn to search for jobs, this social media network. [...] "ends up having many vacancies which are a bit dubious and starts to be an impractical platform to look for a job, as many vacancies are posted, too many of which are vacancies at anonymous companies - which makes the search confusing". Facebook is also one of the networks mentioned, although it is used less frequently for this purpose, having only been used by four of the respondents (31 per cent).

Company websites is the second-most-used method in this stage, which was mentioned by 12 of the 13 respondents. Interviewee 2 (24 years old, Bachelors graduate) says that. [...] "as these were companies that knew that they are recognised as being good companies to work for (. . .) as I knew the name of these companies, I decided to look for them directly."

Seven respondents (54 per cent) mentioned that employment websites were used at this stage. This channel is often associated with its advantage of being a way of getting to know a large number of vacancies simultaneously. However, respondents report some disadvantages of using this medium: such as the fact that there is often no specific information about who the employer is, neither the requirements being sought, and also the fact that many websites do not offer the option of filtering the search by education area, which makes the experience less friendly.

Personal contacts play an important role in identifying employment opportunities and were used by 10 of the 13 respondents. Several respondents, such as Interviewee 5 (24 years old, Masters graduate), report that "I frequently ask whether there are job vacancies [...]".

The services of higher education institutions' career departments are used by 10 respondents ( 77 per cent of the respondents). In the perspective of Interviewee 2 (24 years old, Bachelors graduate), this method is useful. [...] "to bring together companies, faculties, and students - as it is a way for faculties to gain recognition by their students and companies as well, and also to improve the communication of their course offer and their recruitment, respectively."

Information collection: social media networks are mentioned by 7 of the 13 respondents as having been used at this stage, with a preference for LinkedIn (4 respondents) and Facebook (2 respondents). The respondents say that when they use social media networks to gather information about organisations, they mainly try to find out how many employees

\section{Job search journey of Portuguese Millennials}


EJMS

25,2

the organisation has, who these employees are, and what actions they routinely carry out with the objective of dynamising the company.

With regards the topic of social media networks, we asked whether the respondents followed the pages of organisations in social media networks that are explicitly dedicated to attracting talent - to which 8 of the 13 respondents responded positively. Respondents consult such pages in the hope of: "[... . finding out whether job vacancies are available" (Interviewee 1, 23 year old, Bachelors graduate); finding information about "[. . .] events that have to do with employees and news about new things that they do [...] whether they win prizes" (Interviewee 3, 23 years old, Bachelors graduate), and "[. . .] reading the testimonies of young people who have just started talking about their experience" (Interviewee 4, 23 years old, Masters graduate). For this purpose, Facebook (used by 6 respondents) was revealed to have a higher success rate than LinkedIn (used by 5 respondents).

Consulting employee reviews of organisations on the various digital platforms was not mentioned by any of the respondents. However, one of the respondents, Interviewee 13 (24 years old, Bachelors graduate), referred to using customer reviews at this stage of the job search process, because she "does not want to work for a company that mistreats its clients".

Job fairs are infrequently used as a channel at this stage of information gathering, and were only mentioned by 2 of the 13 respondents. However, for those respondents who mention having used it, they were satisfied with the amount of information capacity that this tool enabled them to collect [...] "job fairs are good - because people are there who can explain”, Interviewee 6 (23 years old, Bachelors graduate).

Evaluation and shortlist of possible jobs: evaluation by candidates who comprise the sample population was shown to be continuous and individual for each vacancy. That is to say, candidates identify the vacancies, collect information about them, and simultaneously evaluate the data that they collect - applying it immediately if the vacancy is in their interest. Out of the 13, 10 respondents described that they had carried out a continuous evaluation throughout all the phases, rather than just dedicating a specific phase to this evaluation [...] "when I see a vacancy, I evaluate whether to put myself forward as a candidate, or not. I do not make a comparison, as [...] I may then throw away an opportunity if I assume that another job is going to be better, and then it may not even be so." (Interviewee 4, 23 years old, Masters graduate).

Regarding the preparation of a shortlist of possible job opportunities, only one respondent claims to have done this, although this respondent's list was not prepared as an evaluation and comparison of vacancies, but rather for the pupose of the organisation and planning of application deadlines. [...] "I literally wrote a list of possible vacancies to which I could apply, even though certain vacancies were not yet open on that specific date, although they would open soon" (Interviewee 10, 23 years old, Bachelors graduate).

Application's intention and applications: The vast majority (10 of the 13 respondents) consider it important that organisations display willingness to clarify doubts before candidates submit their application. According to Interviewee 12 (24 years old, Masters graduate), this contact is important [... " to understand whether or not we identify with the vacancy and if it meets our expectations - as this also saves the company time in recruitment, because they can manage expectations better." With regards, the preferred channel for making this type of contact, email and telephone were the most common - with both being mentioned by 5 respondents.

Once the application has been submitted by the respondents, which is mainly carried out on companies' websites, or by using company e-mails, the candidates prefer to utilise platforms or contacts which are directly related with the companies, rather than use intermediaries - such as employment websites - where often the route of the application 
process is unknown. The submission of an application through a company website is mainly done through the filling out of application forms which are available online. [... " these were mostly platforms of this kind, where you had several fields to fill in, and where you had the chance to attach your curriculum" (Interviewee 6, 23 years old, Bachelors graduate) - or by creating profiles within the websites themselves [...] "PwC, EY, and Daimler all make you create a profile inside their page, where you can place all of your documents - all your information, and thus they have access to your information directly on their page" (Interviewee 5, 24 years old, Masters graduate). The tendency is thus for this contact to be made by digital means.

Nine respondents report having received an e-mail from organisations confirming receipt of their application - for at least one of the job search processes that they have experienced. The vast majority ( 8 respondents) affirm that even though it is automatic, they find this contact to be useful, as they can see whether their application has been effectively submitted. With regarding how this contact should be made, more than half of the respondents (7) who consider this information to be advantageous prefer to receive the information by email.

Persuasion: The vast majority of respondents (12) affirm that it is useful for companies to get in contact during the recruitment and selection process, to clarify any doubts that may arise during the selection tests. The preference is for this contact to be made by telephone (mentioned by 6 respondents), followed by e-mail (mentioned by 5 respondents). The reason given for the need for the contact to be made by telephone is mainly the creation of greater proximity. According to Interviewee 2 (24 years old, Bachelors graduate), in the case of an email [...] "this creates a certain distance and does not allow for such a good connection." Those who prefer to be contacted by e-mail say that this helps keep the process more professional and, according to Interviewee 3 (23 years old, Bachelors graduate), a telephone call would be [...] "too intrusive".

All respondents stated that the selection stages allow them to gather important information about the company they are applying for, especially if this selection is carried out in person. The contact that is had with the employers throughout the selection stages allows the candidates to collect information which otherwise would not be possible to collect. For this stage involves much more than just searching for information on the organisation's digital channels - for it represents an opportunity to briefly experience getting to know the organisation's environment. According to the respondents, this contact can even make them change their minds about wanting to work in a specific place, as stated by Interviewee 3 (23years old, Bachelors graduate) [...] "we do not take long to gain a perception of a place - we soon have a perception of the people who work there, at least of their face when they are working which shows whether they are content, or not; we gain a different impression of the place and we can imagine ourselves working there, or not".

Regarding the holding of interviews, the preference is for it to be carried out in person, with 12 of the respondents sharing the opinion of Interviewee 12 (24 years old, Masters graduate), who said that in this way the interview [...] "allows us to know better the opportunity itself and also enables us to get to know each other better and to create more empathy with the recruiter". Resorting to digital contact to carry out an interview is seen by the respondents to be impersonal and does not permit a true understanding of each party.

Outcomes: the vast majority of the respondents (10 of the 13) replied that when they are selected, they like this result to be transmitted in a more individual and personalised way. Their preference is for a telephone call [...] "I think it makes more sense to inform the candidate by a telephone call, as this is the potential start of a closer and more personal contact with someone from the company" (Interviewee 1, 23 years old, Bachelors graduate).

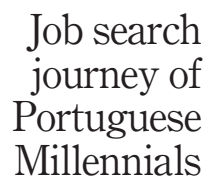

63 
EJMS

25,2

64

In the opinion of all the respondents, when candidates are not selected, it is expected that, at least, this information be transmitted to the candidate. However, according to the respondents, the tendency is for companies to simply not get back in touch with the unselected candidates. In the opinion of the respondents, this information should be transmitted by e-mail (8 respondents), or by telephone (3 respondents). In addition, more than half of respondents said they would welcome feedback from the company as to why they were not selected, and how they could improve [... "I think it is always beneficial for the person to know why it did not go well, what happened, and why the company made that decision" (Interviewee 2, 24 years old, Bachelors graduate). The communication of not being selected and the way that this is done is extremely important from the viewpoint of the candidate, and, according to 12 of the 13 respondents, this can even influence the cadidatés future interest in re-applying to the company, because [...] hx201C; if the company does not say anything when people are selected for the job, people soon get the idea that the company does not have any consideration for its employees." (Interviewee 3, 23 years old, Bachelors graduate).

\section{Discussion of results and conclusions}

The main objective of this study is to map the route and communication channels used by the Millennial generation in the job search process. In response to this objective, the "job search journey" (Figure 2) is presented for the Portuguese Millennial generation.

Figure 2 illustrates that during carrying out job search and job awareness activities, the first point of contact with the organisation that is chosen by respondents tends to influence their subsequent contact points. For example, on one hand, those respondents who, during the first stage of their job search, identify employment opportunities on social network sites, on employment websites, or through higher education institutions, follow one of two routes: the immediate submission of their application, when they already know the organisation, or a search for the company in search engines, if they do not know the organisation, which leads to visiting the company website to gather information about the company's activity to enable them to decide whether to submit their application, or not. On the other hand, those respondents who use their personal contacts as a source of knowledge of employment opportunities follow one of two alernative routes:

Figure 2.

Job search journey for Portuguese Millennials

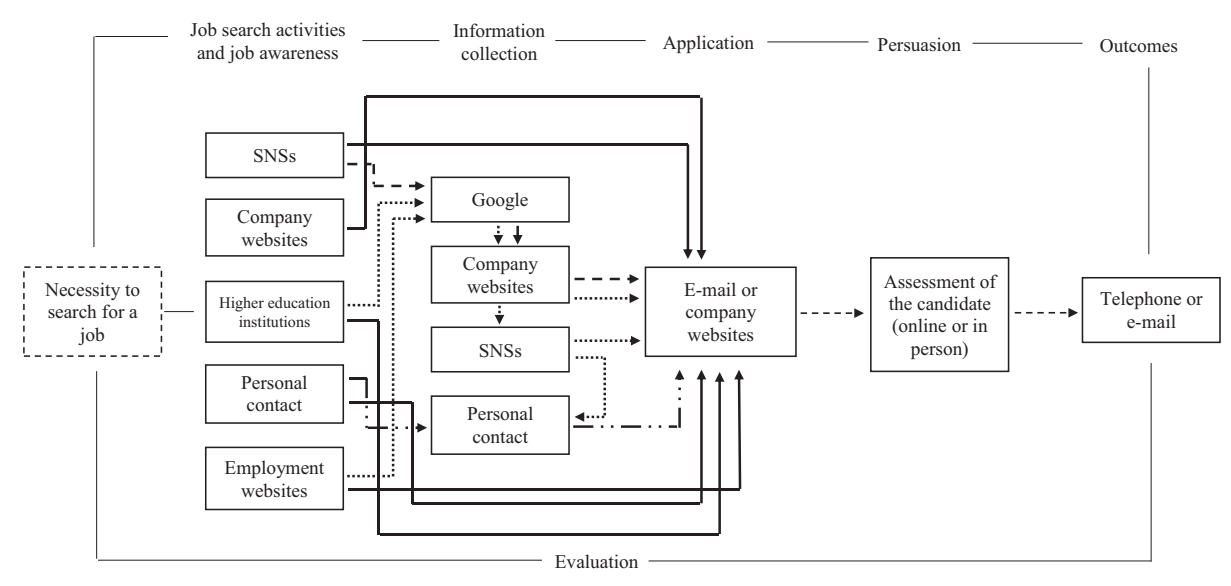


(1) If they already know the organisation, they submit their application immediately.

(2) If they do not know the company in question, then they make use of their personal contacts who work for the company and/or who informed them of the job opportunity, to know more about the organisation prior to submitting their application.

Job search
journey of
Portuguese
Millennials

65

Finally, those individuals who find employment opportunities through companies' websites tend to decide on the spur of the moment whether to submit their application, or not - as they tend to only directly visit websites of companies where they could see themselves working.

During the information collection stage, in cases where job vacancies are not found on social network sites or through personal contacts, and when candidates do not know the organisation, respondents also visit the social networks of the company - after having visited the company website. Often, even during this stage, social network sites are the preferred medium for contacting friends and/or acquaintances who are currently working for, or have previously worked for the organisation.

The application phase is essentially carried out by means of e-mails or on organisations' websites. During both the persuasion and outcome phases (which includes the selection tests, which are either conducted online or in person, and also the communication of the recruitment outcome by the organisation), the organisation's principle means of contact with the candidate is by telephone (in the case of selection) and by e-mail (in the case of nonselection).

The evaluation phase by the candidate is a constant throughout the job search process. Candidates evaluate the organisation in several ways, ranging from the way that the company communicates their job vacancies, through to the way that their selection or nonselection decision is communicated. Even after the submission of their application, candidates evaluate their subsequent contacts with the organisation, as well as the way that the job search process is carried out, including the selection stages, and even the corporate atmosphere and organisational environment, should these steps be performed in person.

Accordingly, the interview process shows that both the initial contact with the company and whether the candidate already knows the company, or not, will later define the contact points that follow - and therefore the importance for organisations to understand the fine details of the job search process. Organisations need to adapt the way that they carry out their recruitment and selection processes, as they possess knowledge of the ways and the points of contact which candidates commonly use throughout the course of job searches.

Consequently, the first step should be to create a company website for the communication of job vacancies and for the disclosure of the way of working of the organisation, and also detail the functional and symbolic attractions of working for the company, especially as this was one of the most-mentioned media throughout the interviews during the various stages of the job search process. According to Chaker (2018), it is important for companies to define their employer value proposition well, i.e. the set of benefits, associations, and values which positively influence both candidates and employees, by making the most of their career website and through promoting the value proposition in such a way that captures the attention of potential candidates. Preparation for interviews shows that what candidates are looking for when visiting career websites is, above all, very detailed information about the company's business, as well as its mission, vision, and values, and also the testimonies of current or former employees, together with more detailed information about the job vacancy. 
EJMS

25,2

The creation of a social network page which is exclusively dedicated to attracting talent also proves to be important from the point of view of the candidate. This type of page leads to a greater engagement between both parties, as it is here that the candidates have the opportunity to closely follow all the initatives of the organisation and can demonstrate their liking of the posts that communicate these initiatives and place questions more directly (Chaker, 2018). Therefore, to capture the attention of the Millennial generation, companies must principally take every opportunity to effectively communicate the available job vacancies. It is not enough to just post them on the company's website - they should also always be mentioned in the social network pages, as most candidates do not consult company websites frequently. Companies must also invest in the publication of content which is related to their events and activities - both externally, to their clients, and internally, to their employees - and also in sharing news, interesting facts, and achievements of the organisation. Another important aspect for candidates is the opportunity to have access to testimonials from employees about their experience working for the company. It is important for organisations to share this content, both on social networks and on company websites, as it represents an opportunity to publicise their value proposition (Chaker, 2018).

The use of personal contacts throughout the various stages of the job search was frequent. Organisations should bear in mind the importance that employees have in recommending the company that they work for to friends, family and/or acquaintances. Employees of an organisation should be recognised as being a credible source of first-hand information regarding how a particular organisation actually works. According to Petrone (2015), it is easier for the public to believe that a certain company is in fact a good place to work if such feedback actually comes from an employee.

In conclusion, this exploratory study suggests that those contact points that exist between candidates and organisations throughout the job search process follows a pattern of a set of possibilities (which we called the "job search journey"). The recognition and mapping of this pattern by organisations can help them improve the effectiveness of their recruitment strategies, by facilitating the use and management of specifically targeted recruitment channels.

\section{Limitations}

While these findings advance our understanding of the job search activities of the job seekers, there are some limitations that need to be considered. First, although this study represents a relevant step in extending the knowledge provided by previous research on job search activities, the retrospective responses associated with contact points can contain memory lapses. Future studies would benefit from a research design which follows each individual's job search journey from the very beginning. Second, the study's sample is a convenience sample, and therefore the interpretation of the results has to be treated with caution. Finally, the sample is composed mainly of individuals who reside in Lisbon, which may not represent the entire Portuguese population of Millennials. Future research should address this issue, including through the use of representative samples.

\section{Future research opportunities}

Although this study presents preferred points of contact for the Portuguese Millennials generation, carrying out more empirical studies would be useful to complement and validate our results. On one hand, such research could extend our study to other generations, or to other groups of individuals, such as those with different levels of education. On the other hand, Acikgoz (2018) suggests in his paper that the characteristics of candidates influence 
their job search activities, which in turn influence the entire job search process. In our view, these same characteristics can influence the job search journey. In addition, it would be interesting to see how organisations could improve candidates' experience throughout the whole job search journey. Finally, it would also be useful to explore how this job search journey takes place in other countries and in other cultures.

\section{References}

Acikgoz, Y. (2018). Employee recruitment and job search: Towards a multi-level integration. Human Resource Management Review, 29(1), 1-13.

Acikgoz, Y. \& Bergman, S.M. (2016). Social media and employee recruitment: Chasing the run away bandwagon. In R. N. Landers \& G. B. Schmidt, (Eds), Social media in employee selection and recruitment: Theory, practice, and current challenges, Switzerland: Springer International Publishing Switzerland, 175-195.

Addison, J. T. \& Portugal, P. (2002). Job search methods and outcomes. Oxford Economic Papers, 54(3), 505-533, doi: 10.1093/oep/54.3.505.

Backhaus, K. \& Tikoo, S. (2004). Conceptualizing and researching employer branding. Career Development International, 9(5), 501-517, doi: 10.1108/13620430410550754.

Bae, J. \& Mowbray, O. (2019). Millennial generation's job search activity and job quality: Findings from the national longitudinal survey of youth. Journal of Social Service Research, 45(2), 269-277, doi: 10.1080/01488376.2018.1480553.

Barber, A.E., Daly, C. L., Giannantonio, C. M., \& Phillips, J. M. (1994). Job search activities: An examination of changes over time. Personnel Psychology, 47(4), 739-766, doi: 10.1111/j.17446570.1994.tb01574.x.

Beam, E. A. (2016). Do job fairs matter? Experimental evidence on the impact of job-fair attendance. Journal of Development Economics, 120, 32-40, doi: 10.1016/j.jdeveco.2015.11.004.

Chaker, N. (2018). The definitive guide to recruitment marketing. Retrieved from https://beamery.com/ academy/recruitment-marketing-guide

Corcoran, M., Datcher, L., \& Duncan, G. J. (1980). Most workers find jobs through word of mouth. Monthly Labor Review, 103(8), 33-35.

Doster, L. (2013). Millennial teens design and redesign themselves in online social networks. Journal of Consumer Behaviour, 12(4), 267-279, doi: 10.1002/cb.1407.

EY. (2015). Global generations: a global study on work-life challenges across generations. Retrieved from www.ey.com/Publication/vwLUAssets/Global_generations_study/\$FILE/ EY-global-generations-a-global-study-on-work-life-challenges-across-generations.pdf

Howardson, G. N. \& Behrend, T. S. (2014). Using the internet to recruit employees: Comparing the effects of usability expectations and objective technological characteristics on internet recruitment outcomes. Computers in Human Behavior, 31, 334-342, doi: 10.1016/j. chb.2013.10.057.

Jansson, K. (2016). Online recruitment and Millennials: Recruitment communication and online assessment (Unpublished master's thesis). University of Oulu, Oulu.

Kanfer, R., Wanberg, C. R., \& Kantrowitz, T.M. (2001). Job search and employment: A personalitymotivational analysis and Meta-analytic review. Journal of Applied Psychology, 86(5), 837, doi: 10.1037/0021-9010.86.5.837.

Kotler, P. \& Armstrong, G. (2018). Principles of marketing, 17th edition, Global Edition., Harlow: Pearson Education Limited.

Lune, H. \& Berg, B. L. (2017). Qualitative research methods for the social sciences, 9th edition, Global Edition., Harlow: Pearson Education Limited.
Job search
journey of
Portuguese
Millennials 
EJMS 25,2

Lyons, S. \& Kuron, L. (2014). Generational differences in the workplace: A review of the evidence and directions for future research. Journal of Organizational Behavior, 35(S1), S139-S157, doi: 10.1002/job.1913.

Newman, D. A. \& Lyon, J. S. (2009). Recruitment efforts to reduce adverse impact: Targeted recruiting for personality, cognitive ability, and diversity. Journal of Applied Psychology, 94(2), 298, doi: 10.1037/a0013472.

Ng, E. S. W. \& Johnson, J. M. (2015). Millennials: Who are they, how are they different, and why should we care?. In R. J. Burke, C. Cooper, \& A. Antoniou, (Eds.), The multi-generational and aging workforce: Challenges and opportunities, Cheltenham: Edward Elgar Publishing Limited, 121-137.

Petrone, P. (2015). Why smart companies want their employees to be social media superstars [blog content]. Retrieved from https://business.linkedin.com/talent-solutions/blog/2015/06/why-smartcompanies-want-their-employees-to-be-social-media-superstars

Prajapati, B. (2016). Social media: Changing employee recruitment. International Journal of Recent Trends in Engineering \& Research, 2(11), 161-166.

Richards, L. (2015). Handling qualitative data: a practical guide, London: SAGE Publications Ltd.

Rosenbaum, M. S., Otalora, M. L., \& Ramírez, G. C. (2017). How to create a realistic customer journey map. Business Horizons, 60(1), 143-150, doi: 10.1016/j.bushor.2016.09.010.

Rudolph, C. W., Rauvola, R. S., \& Zacher, H. (2018). Leadership and generations at work: A critical review. The Leadership Quarterly, 29(1), 44-57, doi: 10.1016/j.leaqua.2017.09.004.

Saunders, M., Lewis, P., \& Thornhill, A. (2016). Research methods for business students, 7th ed., Harlow: Pearson Education Limited. ISBN: 978-1-292-01662-7

Smith, A. D. \& Rupp, W. T. (2004). Managerial challenges of e-recruiting: Extending the life cycle of new economy employees. Online Information Review, 28(1), 61-74, doi: 10.1108/ 14684520410522466.

Twenge, J. M., Campbell, S. M., Hoffman, B. J., \& Lance, C. E. (2010). Generational differences in work values: Leisure and extrinsic values increasing, social and intrinsic values decreasing. Journal of Management, 36(5), 1117-1142, doi: 10.1177/0149206309352246.

Uggerslev, K. L., Fassina, N. E., \& Kraichy, D. (2012). Recruiting through the stages: A Meta-analytic test of predictors of applicant attraction at different stages of the recruiting process. Personnel Psychology, 65(3), 597-660, doi: 10.1111/j.1744-6570.2012.01254.x.

Weber, A. \& Mahringer, H. (2008). Choice and success of job search methods. Empirical Economics, 35(1), 153-178.

Weiss, R. S. (1994). Learning from strangers: the art and method of qualitative interview studies, N.Y: The Free Press.

Wolny, J. \& Charoensuksai, N. (2014). Mapping customer journeys in multichannel decision-making. Journal of Direct, Data and Digital Marketing Practice, 15(4), 317-326. 


\section{Appendix 1}

\begin{tabular}{ll}
\hline Phase & Sub-phase \\
\hline Warm-Up & Sociodemographic \\
questions & data
\end{tabular}

Questions

1. I kindly ask you to introduce yourself by stating your name and talking a little bit about you and about your academic and professional career.

2. What city do you live in?

3. How old are you?

4. What is the highest academic level you have completed? What is your field of study?

Employment status 5. What is your current professional status?

6. (If employed) How did you hear about your current job?

7. (If not employed) Are you currently actively looking for a job?

8. (If 'yes') How long have you been looking for a job? How many applications have you submitted? To which companies?

9. (If 'no') Have you been looking for a job during the past two years?

For how long? How many applications did you send? To which companies? What was the last recruitment process you went through?

Attraction Job search activities In this first phase, we will focus on the moment you decided that you and job awareness wanted to start your job search, even though you were not aware of any job vacancy or specific employer.

10. Describe this process. What was the first thing that you did when you decided you wanted to start your job search? And after that? What sources did you search for job opportunities?

11. When you started looking for a job, were there any particular companies that came to your mind as potential employers or places where you would like to work? What do you think led you to consider these companies?

12. By focussing on Company $\mathrm{X}$, to which you indicated that you submitted your $\mathrm{CV}$, please recall the time when you became aware that there was a possibility of employment with this company. How did happen? Where did you find out about this vacancy? Has this happened with the other companies to which you have sent your CV? 13. In your opinion, and according to your experience, where and how should organisations advertise their job offers to reach the younger generation?

Information collection This phase refers to the moment when the existence of a company or job vacancy is discovered and includes the collection of more detailed information about this opportunity.

14 . When you knew about the job opportunity in company $\mathrm{X}$, what did you do next? Did you search more about the position and the company? Describe how you carried out this search, and which sources you used.

15. Was the process similar for all the companies which you applied to? Is this what you usually do? Have you ever used a different process? Describe this process please.

16. What do you consider to be the major influence on how you idealise the company that you would like to work for?

17. In a recruiting process, do you think it is important for companies to keep their websites and social network pages up-to-date with relevant content? Why?

Table A1. (continued) 


Phase Sub-phase Questions

Selection Evaluation and shortlist of possible jobs

This is the stage when, after collecting information about vacancies and employers, candidates evaluate the strengths and weaknesses of each of the options for which information has been previously collected, and then they decide whether or not to include these in their list of potential employment opportunities.

18. Thinking about your job search process, how did you evaluate the information collected?

(Did you evaluate your options one-by-one as you collected the information about each one, or did you first gather information about all the potentially interesting options you found and then evaluated them by comparing them to each the information about all the available options, and then decide which ones to send your CV to?) What do you usually do in general?

19. What criteria do you consider to be the most important when choosing your next job?

20. Thinking about your last job search, describe what happened after identifying, analysing, and evaluating a number of job vacancies or employers

Application intention From the shortlist of potential employers, there are intentions of and Applications application, which may or may not materialize.

21. Before submitting your application, do you consider that it is important to have prior contact with the organisation, in order that you can ask questions about the position? Why? How would do you prefer this contact to be made?

22. Please describe how your application process to Company X went, to which you sent the CV. How did you physically submit your $\mathrm{CV}$ to the company?

23. Is this what you usually do? Have you ever opted for a different process? Please describe this process.

24 . Did you receive any contact from any of the companies that you applied to immediately after submitting your application? What kind of contact was this? How was it made?

25. Thinking about how communication between companies and candidates is carried out, what do you think an organisation should do, right from the moment when an applicant submits their application, through to the time they are called, for example, for an interview or another type of selection test, to convey a good image of the company to the candidates?

Attrition Persuasion This phase encompasses all interactions carried out between the applicant and the company which are persuasive attempts by both parties to be the selected candidate or a chosen organisation, including interviews and psycho-technical tests, etc.

26. Thinking about the selection process you experienced for company $\mathrm{X}$, please describe in detail all the contacts that existed between you and the company during all the stages of the recruitment process. Please describe each of the steps of recruitment.

27. Did the recruitment stages or contacts differ for any of the companies to which you sent the CV? If 'yes', please describe how. 


\begin{tabular}{lll}
\hline Phase & Questions & Job search \\
journey of \\
28. During the selection tests, when there are technical and & & $\begin{array}{c}\text { Portuguese } \\
\text { psychotechnical tests, do you prefer that these are carried out in } \\
\text { person at the company's premises, or do you prefer to do it online? } \\
\text { Why? }\end{array}$ \\
29. When you are selected for an interview with a potential employer, \\
do you prefer this be carried out in person at the company's premises, \\
or do you prefer to do this online? Why? \\
30. What do you do to prepare for a job interview? What tools or \\
sources do you use? \\
31. Do you like to receive the contact of the person responsible for the \\
recruitment process of the organisation, in order that you can ask \\
questions about the process itself? If so, how do you like this contact to \\
be made? \\
32. Do you think that the contact between candidates and companies \\
during the recruitment and selection process, whether in person or not, \\
always allows you to gather information which is important for your \\
decision to work at a particular location? If "yes", how? If "not", why? \\
Outcomes are the results of the job search process, which may be either \\
being selected or not being selected for the vacancy. \\
33. Going back to the selection process that you experienced with \\
company X, describe what happened from the moment you completed \\
all the selection phases, up until you were informed whether you had \\
been selected, or not. \\
34. Did the same process occur with the other companies? has anyone \\
made you aware of the outcome of your job application in a different \\
way? how? \\
35. In cases when you have not been selected, what do you expect the \\
recruiting company to do? is that what happens in reality? \\
36. Do you expect the company to transmit the decision regarding \\
whether you have been selected, or not, in a different way? How? \\
37. Do you think that the way the company deals with the \\
communication of the results of a recruitment and selection process \\
influences the company's image? How? Why? Do you feel that this can \\
influence your future interest in re-applying to the same company, or \\
even, if selected, your decision to accept an offer?
\end{tabular}




\section{EJMS \\ 25,2}

Appendix 2

\begin{tabular}{ll}
\hline Category & Subcategory \\
\hline Job search & Social network \\
activities and job & sites \\
awareness &
\end{tabular}

Interview excerpts

"[LinkedIn] it is a way for me to be aware of some vacancies, and in fact, there are certain opportunities every week." (Interviewee 5, 24year-old); "LinkedIn Jobs was also where I looked for opportunities." (Interviewee 6, 23-year-old); "Sometimes I also looked at a few pages on Facebook where companies had pages for careers - for example, Nestlé Careers." (Interviewee 4, 23-year-old); "I'm on Facebook in a group of my Masters class, where people sometimes place opportunities." (Interviewee 6, 23-year-old); "[Facebook] I put a like in certain pages, for example, in the ekonomista.pt, which sometimes launched publications with job offers." (Interviewee 10, 23-year-old)

Company "Being companies that I recognised as being good companies to websites work for - this was interesting, as they seemed to fit in with what I was looking for - a more innovative and dynamic company. Knowing the names of these companies, I decided to search or them directly." (Interviewee 2, 24-year-old); "Sometimes, I would sporadically go to a company to see whether there were any open opportunities (such as L'Oréal), and I'd try and search, as these are companies that mean the most to me.” (Interviewee 5, 24-year-old); "This was my first reaction, so to speak, as I didn't know where to look. So there it is, I mean to say, I wanted to see if the companies with a better reputation had something that interested me, or whether they offered a job that I wanted and which I could obviously apply for.” (Interviewee 11, 24-year-old)

Personal contacts "I frequently ask if there are vacancies and they then tell me 'yes' and they send me the job specification." (Interviewee 5, 24-year-old); "People talked about opportunities and I would see what it was and then apply for it if it was in my interest.” (Interviewee 6, 23-year-old); "I talked to my friends who were in the companies and asked: Look, do you guys need anyone?"” (Interviewee 12, 24-year-old).

Job fairs $\quad$ "I went to the ISEG [Lisbon School of Economics and Management] job fair, which was of value to better understand what was available in the job market. I think that taking notice of the vacancies that exist is one of the options." (Interviewee 1, 23-year-old); "Often the people themselves [employees] were not aware of the vacancies that their company had, and it seemed more a matter of brand awareness than properly publicising the company as a place to go to work." (Interviewee 4, 23-year-old); "I went to a job fair once at ISCTE [University Institute of Lisbon]. By the way, I also went to one at ISEG once - mainly just to be aware of the companies that were in contact with universities." (Interviewee 5, 24-year-old)

Higher education "In my ISEG institutional email I received alerts of what companies institution were looking for." (Interviewee 1, 23-year-old); "The first thing I did was to look at the university platforms, both of ISCTE and NOVA [Universidade Nova de Lisboa]. This is where I began to explore and discover what currently existed in the market." (Interviewee 4, 23year-old)

Table A2.

mples of the coding structure and of the interview excerpts
"At the moment I am registered at the Job Centre as unemployed, in case something appears." (Interviewee 8, 23-year-old); "For example, I always worked in stores and customer service and there was a time 


\begin{tabular}{ll}
\hline Category & Subcategory \\
\hline & \\
$\begin{array}{ll}\text { Information } \\
\text { collection }\end{array}$ & $\begin{array}{l}\text { Internet search } \\
\text { engines }\end{array}$
\end{tabular}

Company

websites

Social network sites

Personal contacts I think that if we have a friend or relative who works for a company

Evaluation and Continuous shortlist of assessment possible jobs and who really gives us a very positive perspective on what it's like to work in that company, then we can be influenced by that person." (Interviewee 2, 24-year-old); "When my closest friends started working, I wondered if they liked being at their company, based on the conditions they had.” (Interviewee 3, 23-year-old); “If I knew someone who worked for the company, I would sometimes ask them for some kind of feedback ..." (Interviewee 4, 23-year-old)

when I received a proposal for a training course that had to do with aesthetics." (Interviewee 7, 26-year-old); "In terms of helping to find a job, it does not help at all." (Interviewee 12, 24-year-old)

At this stage, prior to applying for a job, I just looked for the location of the company on Google, which is an important factor for me in a job search." (Interviewee 1, 23-year-old); "I knew what the business was, but I did not know whether the business would be just that, or whether it had more areas. I searched a little bit more about the history, location, mission, and values of the company." (Interviewee 10, 23-year-old)

if we're talking about a company that I do not really know, for example, there was a particular case of a small consultancy, then I would search the name of the consultant before applying. ... What does it do? . . f for as I did not know the company - I had never heard year-old); "There were other companies where I saw a job, but I did not know the company, and then I would search what the company did, to see if it was in my interest. By looking at the website it was more or less easy to judge whether it was great, or whether it was not great, and whether it could be good for working in Human Resources - or not." (Interviewee 6, 23-year-old); "I looked and went to the website - I was literally searching everything - as well as anything else there was to find on the website." (Interviewee 12, 24year-old)

"In these cases, what I tried to do was - which is another important feature of LinkedIn - to see whether there was anyone who works there whom I knew - which I might not have knowledge about, due there being a recent change." (Interviewee 2, 24-year-old);

"Especially LinkedIn, and sometimes also the Facebook page of companies - to see whether they were dynamic companies, or if they had events. ... (Interviewee 4, 23-year-old)

I would see the vacancy, and if I was interested, I would apply for it immediately. I did not collect information on all of the vacancies, but rather chose the ones to which to send my application .... No, I sent it immediately." (Interviewee 13, 23-year-old); "As I look at a vacancy, I evaluate it - and then apply for it .... or not. I do not make a comparison by job offer" (Interviewee 4, 23-year-old); "I made such an assessment, but this was done, as I was applying for various things and looking for opportunities." (Interviewee 2, 24year-old) of it; I went direct to the company's website." (Interviewee 5, 24-

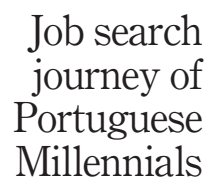

73 


\begin{tabular}{lll}
\hline Category & Subcategory & Interview excerpts \\
\hline Evaluation & "I did not separate the issue of candidate and consumer - I was
\end{tabular}

criteria

much more interested about the consumer issue." (Interviewee 1, 23-

year-old); "Perspectives of the future, in other words, whether to stay in the company, the opportunity to know the company, and to be

\section{4}

Application' Pre-application intention able to perceive what is going on in the company, rather than being merely fixed in an area.” (Interviewee 2, 24-year-old); “The balance between work and personal life - as I think a job from nine to six is a bit outdated." (Interviewee 3, 23-year-old); "At this time, there is no doubt that it is financial security - and the ability to progress." (Interviewee 5, 23-year-old)

"Having a pre-application contact to clarify any issues was important .... This was important, as it would give you a sense of a certain interest in the company by the candidates and also demonstrated taking some care with regard to the candidates." (Interviewee 1, 23-year-old); "This is important, as we often have an idea of a job vacancy, or internship, or even of the company itself that is not correct - for if we had prior contact we could make an evaluation which we tend to only do after an interview." (Francisca Mendonça, 23-year-old); "I think it would be beneficial to know the company a little bit more - for then we can ask questions without having to wait for a first interview - to see if we identify with the vacancy, or not." (Interviewee 12, 24-year-old)

Application "In the case of José de Mello [company], after hearing that they had opened applications through ISEG's institutional e-mail, I then went to their website to submit my application." (Interviewee 1, 23-yearold); "In the case of Playstation [company], I sent my application through the ISEG job search application." (Interviewee 1, 23-yearold); "I also applied for some vacancies through LinkedIn." (Interviewee 2, 24-year-old); "In the case of Samsung [company], I sent my application directly to a university colleague by email." (Interviewee 2, 24-year-old); "Companies usually have their own email address for receiving applications.” (Interviewee 7, 26-yearold)

Post-application "Most consultants have a 'no-reply' email, where they tell me: Thanks for your application. Please do not reply to this email. We are going to review and then get in touch with you. Therefore, you more or less have the notion that your application has been received." (Interviewee 5, 24-year-old); "The answer is very important, even if it is automatic - just for the person to know that their curriculum has reached its destination." (Interviewee 6, 23year-old); "By e-mail they told me that they had received my application, and that they were going to analyse it and that they would soon give me feedback." (Interviewee 13, 23-year-old)

Persuasion Selection tests "I prefer this to be done online, because I think it's a good way for them to do a sort, which takes up little time and also turns out to be a facilitator." (Interviewee 2, 24-year-old); "From my point of view, I'd rather the test was online - as we are a little more intimidated in person, and are more nervous, and we ended up not showing what we really should have shown.” (Francisca Mendonça, 23-year-old);

Table A2. 


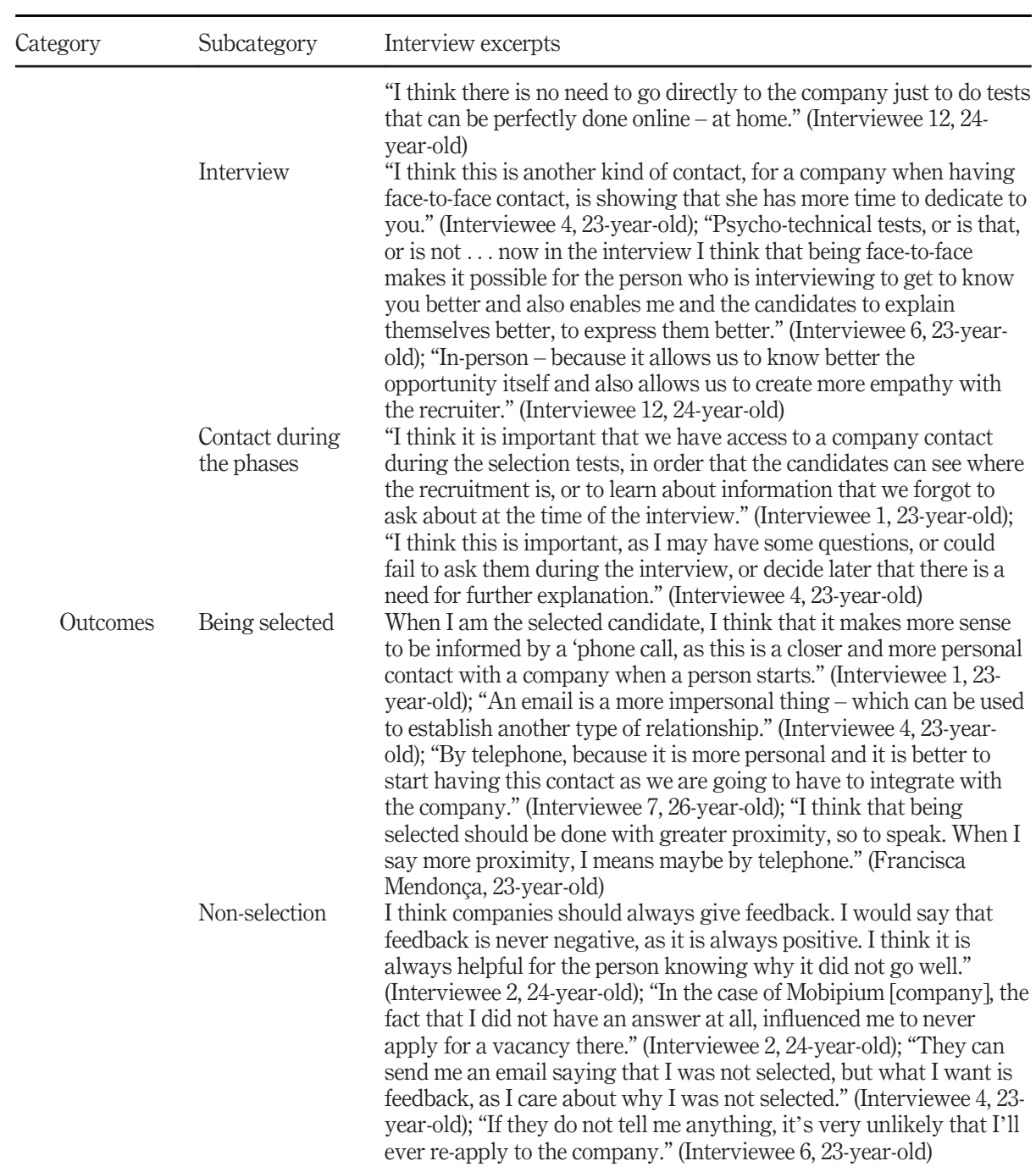

Contact during the phases the recruitment is, or to learn about information that we forgot to ask about at the time of the interview." (Interviewee 1, 23-year-old); important, as I may have some questions, or could need for further explanation." (Interviewee 4, 23-year-old) to be informed by a "phone call, as this is a closer and more personal contact with a company when a person starts." (Interviewee 1, 23year-old); "An email is a more impersonal thing - which can be used to establish another type of relationship." (Interviewee 4, 23-yearold); "By telephone, because it is more personal and it is better to start having this contact as we are going to have to integrate with the company." (Interviewee 7, 26-year-old); "I think that being selected should be done with greater proximity, so to speak. When I more proximity, I means maybe by telephone." (Francisca inça, 23-year-old) feedback is never negative, as it is always positive. I think it is always helpful for the person knowing why it did not go well." (Interviewee 2, 24-year-old); "In the case of Mobipium [company], the fact that I did not have an answer at all, influenced me to never apply for a vacancy there." (Interviewee 2, 24-year-old); "They can send me an email saying that I was not selected, but what I want is year-old); "If they do not tell me anything, it's very unlikely that I'll ever re-apply to the company." (Interviewee 6, 23-year-old)
Table A2.

\section{Corresponding author}

Sandra Miranda can be contacted at: sandraoliveira@iseg.ulisboa.pt 